Volume 3 • Nomor 2 • Februari 2020

Pege (Hal.) : $54-61$

(C) Universitas Pamulang

JL.Surya Kencana No.1 Pamulang, Tangerang Selatan - Banten

website. :

Telp. (021) 7412566, Fax (021) 7412491

http://www.openjournal.unpam.ac.id/index.php/JPK Email : jurnalmarketing.unpam@gmail.com

\title{
Pengaruh Kualitas Layanan dan Harga Bersaing Terhadap Kepuasan Pelanggan Tangki Air Penguin Pada Toko Bahan Bangunan di Gading Serpong
}

\author{
Retno Wulansari ${ }^{1}$, Ramdan Novianto ${ }^{2}$ \\ Universitas Pamulang, \\ dosen00568@unpam.ac.id, ramdannovianto@gmail.com
}

\begin{abstract}
Abstrak. Produsen produk tangki air menghadapi tantangan untuk memberikan pelayanan yang berkualitas dan harga bersaing untuk mendapatkan kepuasan konsumen. Penulis melakukan penelitian ini, dengan tujuan untuk dapat mengetahui bagaimana kualitas pelayanan dan harga bersaing, serta kepuasan pelanggan produk Tangki Air Penguin pada Toko Mitra 10 Gading Serpong, serta untuk mengetahui apakah kualitas pelayanan dan harga bersaing, mempengaruhi kepuasan pelanggan pada produk Tangki Air Penguin? Metode penelitian yang di gunakan adalah metode assosiatif dengan pendekatan kuantitatif. Metode analisis data menggunakan analisis regresi linier sederhana, berganda, uji koefisien korelasi, dan analisis koefisien determinasi. Berdasarkan hasil penelitian pada produk tangki air merek Penguin, kualitas pelayanan dan harga bersaing, serta kepuasan pelanggan, sudah baik. Hasil penelitian dengan menggunakan analisis regresi linier berganda, penulis mendapatkan persamaan regresi, yaitu; $Y=0,158+0,533 X 1+0,462 X 2$. Hasil koefisien korelasi sebesar 0.842 yang berarti terdapat korelasi yang "kuat" antara kualitas pelayanan, dan harga bersaing, serta kepuasan pelanggan.

Keywords: Harga; Kualitas Pelayanan; Kepuasan Pelanggan
\end{abstract}

Abstract. Water tank product Company facing a challenge to provide quality services and competitive prices to get customer satisfaction. The objectives of this study is to analysis quality of service, and competitive price and customer satisfaction of Penguin Water Tank products at Mitra 10 Gading Serpong Store. Are there relationship between service quality and price to customer satisfaction ? Using associative and quantitative method. Data analysis methods used linear regression, multivariate linier regression, coefficient correlation test, determination coefficient test. The result of this study, service quality, price, customer satisfaction in the water tank Penguin product at Mitra 10 Gading Serpong is good. The results of multiple linear regression analysis obtained a regression equation $Y$ $=0.158+0.533 X_{1}+0.462 X_{2}$. The results of the consideration coefficient of 0.842 which means there is a strong relationship between service quality, price and customer satisfaction.

Keywords: Customer Satisfaction; Price; Service Quality

\section{A. PENDAHULUAN}

Untuk dapat memberikan kepuasan kepada konsumen, perusahaan harus lebih peka dalam memberikan layanan terbaik kepada konsumen. Keputusan mengenai harga akan menentukan keberhasilan atau kegagalan bagi perusahaan. Harga merupakan dasar terbentuknya keuntungan sehingga seluruh perusahaan berusaha memaksimalkannya dengan pengembangan pasar. 
Tabel 1. Data Penjualan Tangki Air Penguin, Pada Toko Bahan Bangunan, Di Sekitar Wilayah Toko Mitra 10 Gading Serpong (Periode November 2018 - Oktober 2019)

\begin{tabular}{lccc}
\multicolumn{1}{c}{ Nama Toko } & Target (Rp) & Penjualan (Rp) & Persentase \\
\hline Depo Bangunan Alam Sutera & 3.000 .000 .000 & 3.945 .360 .000 & $131,51 \%$ \\
\hline Dunia Bangunan BSD & 1.800 .000 .000 & 2.165 .670 .000 & $120,31 \%$ \\
\hline Super Bangun Jaya & 1.800 .000 .000 & 1.927 .650 .000 & $107,09 \%$ \\
\hline Mitra 10 Gading Serpong & 1.800 .000 .000 & 1.268 .550 .000 & $70,47 \%$
\end{tabular}

Sumber : PT. Penguin Trading, tahun 2019.

Tabel 2. Data Penjualan Tangki Pesaing di Mitra 10 Gading Serpong (Periode November 2018 - Oktober 2019)

\begin{tabular}{lcrc}
\multicolumn{1}{c}{ Merk Tangki } & Total (Unit) & Penjualan $(\mathbf{R p})$ & Total (Transaksi) \\
\hline Penguin & 864 & 1.268 .550 .000 & 528 \\
\hline Profil Tank & 126 & 286.540 .000 & 108 \\
\hline DOS & 86 & 197.860 .000 & 74 \\
\hline
\end{tabular}

Sumber: Mitra 10 Gading Serpong, tahun 2019.

Pangsa pasar produk tangki air Penguin mempunyai penjualan paling rendah, dibandingkan dengan penjualan pada toko bahan bangunan pesaingnya, di sekitar wilayah Toko.

Rumusan masalah pada penelitian ini adalah, bagaimana kualitas pelayanan dapat mempengaruhi kepuasan pelanggan pada Toko Bahan Bangunandi Gading Serpong?, bagaimana harga bersaing produk tangki air Penguin, dapat mempengaruhi kepuasan pelanggan pada Toko Bahan Bangunan di Gading Serpong?, seberapa besar kualitas layanan serta harga bersaing dapat mempengaruhi kepuasan para konsumen pada Toko Banhan Bangunan di Gading Serpong?

Penelitian ini bertujuan untuk mengetahui kualitas layanan, serta harga bersaing mempengaruhi kepuasan para konsumen pada Toko Bahan Bangunan di Gading Serpong.

\section{B. KAJIAN LITERATUR}

"Kualitas pelayanan adalah ukuran seberapa bagus tingkat layanan yang diberikan mampu sesuai dengan ekspektasi pelanggan". (Tjiptono, 2016:59)

"Price The amount of money charged for a product or service, the sun of the values then customers exchange for the benefit of having or using the product or service". (Kotler \& Amstrong, 2017:324).

"Kepuasan pelanggan adalah perasaan senang atau kecewa seseorang yang muncul setelah membandingkan kinerja (hasil) produk yang dipikirkan terhadap kinerja yang diharapkan". (Kotler \& Keller, 2016:177). 
Kerangka Berpikir

ISSN NO. (PRINT) 2598-0823, (ONLINE) 2598-2893

Variabel (X1), yaitu (Kualitas

Pelayanan), dengan indikator

1. Kehandalan (Reliability),

2. daya tanggap

(Responsiveness),

3. jaminan (Assurance),

4. perhatian (Emphaty),

5. bukti fisik (Tangibel)

Sumber: Fandy Tjiptono

$(2016 ; 282)$

H3

Variabel (X2), yaitu

(Harga),dengan indikator

1. keterjangkauan harga,

2. daya saing harga,

3. kesesuaian harga dengan kualitas produk,

4. kesesuaian harga dengan manfaat

Sumber: Kotler dan Amstrong $(2017 ; 78)$
Variabel (Y1), yaitu (Kepuasan

Pelanggan), dengan indikator

1. memenuhi harapan pelanggan,

2. memenuhi kebutuhan,

3. Setia pada produk perusahaan

4. merekomendasikan kepada orang lain,

5. menawarkan gagasan dan ide

Sumber: Kotler dan Keller

(2016:138)

Gambar 1; Kerangka Berpikir 


\section{METODOLOGI PENELITIAN}

Penelitian dilakukan untuk produk tangki air merek Penguin pada Toko Bahan Bangunan di Gading Serpong yang beralamat di Jalan Boulevard Raya Gading Serpong Blok Mitra 10, Curug Sangereng, Kec. Kelapa Dua, Tangerang Banten 15820, call center (021) 54217373.

Penelitian Dilaksanakan dari bulan 1 November tahun 2018, sampai dengan bulan Oktober 2019. Populasi penelitian ini adalah pelanggan tangki air Penguin Mitra 10 Gading Serpong. Sampel adalah 85 responden yaitu pelanggan yang membeli tangki air Penguin di Mitra 10 Gading Serpong.

Analisis menggunakan Uji Koefisien Kolrelasi, Determinasi, Linear Regresion, Multivariate Regression.

\section{HASIL DAN PEMBAHASAN}

Berdasarkan pengolahan data-data kuesioner, penulis mendapatkan data mengenai karakteristik pelanggan dari 85 responden, responden dengan jenis kelamin laki - laki 54 atau ( $63,5 \%)$, responden yang mempunyai jenis kelamin perempuan 31 atau $(36,5 \%)$. Kemudian, responden yang dengan usia diantara usia 18 - 30 tahun 57 atau $(67,5 \%)$, usia diantara 31 - 40 tahun 26 atau (30,5\%), dan berusia diantara 41 - 50 tahun adalah 1 atau (1\%). Respondendengan tingkat pendidikan SLTA, adalah 53 atau (62\%), mempunyai tingkat apendidikan diploma 5 atau (6\%), kemudian mempunyai tingkat pendidikan S-1 adalah 24 atau (28\%), dan dengan tingkat pendidikan setara S-2 adalah 3 atau (4\%). Responden Mahasiswa sebanyak 6 orang atau 7\%, responden karyawan swasta sebanyak 51 orang atau 60\%, PNS (Pegawai Negeri Sipil) 2 (2,5\%), Wiraswasta 26 (30,5\%).

Tabel 3. Hasil Pengolahan Regresi Linier Sederhana, Variabel $X_{1}$, Terhadap $Y$

\begin{tabular}{|c|c|c|c|c|c|}
\hline \multirow[b]{2}{*}{ Model } & \multicolumn{2}{|c|}{$\begin{array}{l}\text { Unstandardized } \\
\text { Coefficients }\end{array}$} & \multirow{2}{*}{$\begin{array}{l}\text { Standardized } \\
\text { Coefficients } \\
\text { Beta }\end{array}$} & \multirow[b]{2}{*}{$t$} & \multirow[b]{2}{*}{ Sig. } \\
\hline & $\bar{B}$ & Std. Error & & & \\
\hline 1 (Constant) & 3,562 & 3,008 & & 1,184 & ,240 \\
\hline $\begin{array}{l}\text { Kualitas } \\
\text { Pelayanan }\end{array}$ & ,903 & ,075 & ,796 & 11,96 & ,000 \\
\hline
\end{tabular}

Sumber: Analsis Data

Tabel 3, menghasilkan, " $Y=3,562+0,903 X_{1}$ ". Konstanta 3,562. Perubahan 1 unit $X_{1}$ akan mempengaruhi $Y$, yaitu 0,903 .

Tabel 4. Hasil Pengolahan Regresi Linier Sederhana $X_{2}$, Terhadap $Y$

\begin{tabular}{llllll}
\hline \multicolumn{7}{c}{ Unstandardized Coefficients Standardized Coefficients } & & \\
\cline { 2 - 5 } Model & $B$ & Std. Error & Beta & $\boldsymbol{t}$ & Sig. \\
\hline $\mathbf{1}($ Constant) & $\mathbf{3 , 2 1 1}$ & 2,914 & & 1,102 &, 274 \\
\hline Harga &, 913 &, 073 &, 808 & $\mathbf{1 2 , 4 7 5 , 0 0 0}$ \\
\hline Sumber : Analisis Data & & &
\end{tabular}


Tabel 4, penulis mendapatkan hasil, $Y=3,211+0,913 X_{2}$. Konstanta 3,211. Perubahan 1 unit $\mathrm{X}_{2}$, akan mempengaruhi $\mathrm{Y}$, yaitu 0,913 .

Tabel 5. Hasil Pengolahan Regresi Linier Berganda

\begin{tabular}{|c|c|c|c|c|c|}
\hline \multirow[b]{2}{*}{ Model } & \multicolumn{2}{|c|}{$\begin{array}{l}\text { Unstandardized } \\
\text { Coefficients }\end{array}$} & \multirow{2}{*}{$\begin{array}{l}\begin{array}{l}\text { Standardized } \\
\text { Coefficients }\end{array} \\
\text { Beta } \\
\end{array}$} & \multirow[b]{2}{*}{$t$} & \multirow[b]{2}{*}{ Sig. } \\
\hline & $B$ & Std. Error & & & \\
\hline 1 (Constant) & ,158 & 2,865 & &,- 055 & ,956 \\
\hline $\begin{array}{l}\text { Kualitas } \\
\text { pelayanan } X_{1}\end{array}$ & ,533 & , 109 & ,473 & 4,890 &, 000 \\
\hline $\begin{array}{l}\text { Harga Bersaing } \\
\mathrm{X}_{2}\end{array}$ & ,462 & ,108 & ,414 & 4,275 & ,000 \\
\hline
\end{tabular}

Sumber: Analisis Data

Tabel 5, penulis mendapatkan hasil, " $Y=0,158+0,533 X_{1}+0,462 X_{2}$ ". $X_{1}$ mempengaruhi $\mathrm{Y}$, dengan koefisien 0,533. $\mathrm{X}_{2}$ mempengaruhi $\mathrm{Y}$, dengan koefisien 0,462 pada tangki air Penguin pada Toko Bahan Bangunan di Gading Serpong.

Tabel 6. Hasil Uji Koefisien Korelasi Viabel $X_{1}$ dan $X_{2}$ terhadap Variabel $Y$

\begin{tabular}{lllll}
\hline Model & $\boldsymbol{R}$ & $\boldsymbol{R}$ Square & $\begin{array}{l}\text { Adjusted } \\
\boldsymbol{R} \text { Square }\end{array}$ & Std. Error of the Estimate \\
\hline 1 & $\mathbf{8 4 2}^{\mathbf{a}}$ &, 708 &, 701 & 2,651 \\
\hline
\end{tabular}

Sumber: Analisis Data

Tabel 6, penulis memperoleh nilai $0.842, X_{1}$,dan $X_{2}$, mempunyai korelasi "kuat", terhadap kepuasan para konsumen atau Y pada tangki air Penguin Mitra 10 Gading Serpong.

Tabel 7. Hasil Uji t Pada Variabel $\mathbf{X}_{1}$,

\begin{tabular}{|c|c|c|c|c|c|}
\hline \multirow[b]{2}{*}{ Model } & \multirow{2}{*}{\multicolumn{2}{|c|}{$\begin{array}{ll}\begin{array}{c}\text { Unstandardized } \\
\text { Coefficients }\end{array} \\
\text { B } & \begin{array}{l}\text { Std. } \\
\text { Error }\end{array}\end{array}$}} & \multicolumn{2}{|c|}{$\begin{array}{l}\text { Standardized } \\
\text { Coefficients } \\
T\end{array}$} & \multirow[t]{2}{*}{ Sig. } \\
\hline & & & Beta & & \\
\hline 1 (Constant) & 3,562 & 3,008 & & 1,184 & ,240 \\
\hline Kualitas Pelayanan & ,903 & ,075 & ,796 & 11,967 & ,000 \\
\hline
\end{tabular}


ISSN NO. (PRINT) 2598-0823, (ONLINE) 2598-2893

Tabel 7, penulis mendapatkan hasil dari analisis, $t$ hitung $>t$ tabel $(11,967>1,989)$, variabel bebas yaitu kualitas layanan atau $X_{1}$, mempengaruhi variabel tidak bebas atau kepuasan para konsumen atau $\mathrm{Y}$, pada tangki air Penguin di Toko Bahan Bangunan di Gading Serpong.

Tabel 8. Hasil Uji t Pada Variabel $\mathbf{X}_{2}$,

\begin{tabular}{llllll}
\hline & \multicolumn{2}{l}{$\begin{array}{l}\text { Unstandardized } \\
\text { Coefficients }\end{array}$} & $\begin{array}{l}\text { Standardized } \\
\text { Coefficients }\end{array}$ & $\boldsymbol{t}$ & Sig. \\
\cline { 2 - 6 } Model & $\boldsymbol{B}$ & Std. Error & Beta & & \\
\hline (Constant) & 3,211 & 2,914 & & 1,102 &, 274 \\
\hline Harga &, 913 &, 073 &, 808 & $\mathbf{1 2 , 4 7 5}$ &, 000
\end{tabular}

Sumber: Analisis Data

Tabel 8, penulis mendapat hasil , bahwa t hitung $>t$ tabel atau $(12,475>1,989)$. Variabel bebas harga bersaing, mempengaruhi variabel tidak bebas kepuasan para konsumen pada produk tangki air Penguin Mitra 10 Gading Serpong.

Tabel 9. Hasil Uji F

\begin{tabular}{llllll}
\hline Model & Sum of Squares & $\boldsymbol{d} \boldsymbol{f}$ & $\begin{array}{l}\text { Mean } \\
\text { Square }\end{array}$ & $\boldsymbol{F}$ & Sig. \\
\hline Regression & 1399,320 & 2 & 699,660 & $\mathbf{9 9 , 5 8 9}$ &, $000^{\mathrm{b}}$ \\
\hline Residual & 576,092 & 82 & 7,026 & & \\
\hline Total & 1975,412 & 84 & & & \\
\hline
\end{tabular}

Sumber: Analisis Data

Tabel 9, penulis mendapatkan hasil Fhitung $>$ Ftabel atau $(99,589>2,720)$, kualitas layanan kepada para konsumen, serta harga bersaing, mempengaruhi kepuasan para konsumen produk tangki air penguin pada Toko Bahan Bangunan di Gading Serpong. 
ISSN NO. (PRINT) 2598-0823, (ONLINE) 2598-2893

Tabel 10. Hasil Uji Koefisien Determinasi $X_{1}$ dan $X_{2}$, terhadap $Y$

\begin{tabular}{ccccc} 
Model & $R$ & $R$ Square & Adjusted $R$ Square & Std. Error of the Estimate \\
\hline 1 &, $842^{a}$ &, 708 &, 701 & 2,651 \\
\hline Sumber: Data Analisis & &
\end{tabular}

Tabel 10, penulis mendapatkan hasil 0,708, penulis menyimpulkan, kualitas layanan kepada konsumen, serta harga bersaing, mempengaruhi kepuasan para konsumen atau $\mathrm{Y}$, sebesar $70,8 \%$, nilai sisanya yaitu $29,2 \%$ adalah faktor lainnya.

\section{E. KESIMPULAN}

Berdasarkan hasil analisis, penulis memperoleh kesimpulan, kualitas layanan pada produk tangki air Penguin pada Toko bahan bangunan di Gading Serpong, mempunyai pengaruh positif terhadap variabel tidak bebas, yaitu kepuasan para konsumen, dengan hasil analisis, yaitu " $Y=3,562+0,903 X_{1}$ ". Pada Variabel bebas lainnya, yaitu variabel harga bersaing, mempunyai berpengaruh positif serta signifikan terhadap variabel tidak bebas, yaitu kepuasan pelanggan, sehingga di dapatkan hasil persamaan regresi , yaitu " $Y=3,211+$ $0,913 \mathrm{X}_{2}$ ". Kemudian, variabel bebas yaitu kualitas pelayanan serta variabel bebas lainnya, yaitu harga bersaing, mempunyai pengaruh positif, terhadap variabel tidak bebas yaitu, kepuasan para konsumen, dengan hasil analisis, yaitu " $Y=0,158+0,533 X_{1}+0,462 X_{2}$ ". Kemudian, penulis mendapatkan hasil, analisis dari pengolahan data lapangan, korelasi variabel yang tidak terikat, serta variabel terikat, adalah 0,842", "Kuat". Sedangkan, kualitas layanan konsumen serta harga bersaing, mempengaruhi kepuasan para konsumen, sebesar "70,8\%", nila sisanya yaitu, " $29,2 \%$ ", adalah faktor lain. Penulis mendapatkan hasil Fhitung $>$ Ftabel atau $(99,589>2,720)$, kualitas layanan kepada para konsumen, serta harga bersaing, mempengaruhi kepuasan para konsumen produk tangki air penguin pada Toko Bahan Bangunan di Gading Serpong.

Perusahaan perlu mengadakan evaluasi dan memperbaiki fasilitas dan sarana toko, mulai dari kebersihan lingkungan dan lahan parkir yang memadai, aman dan nyaman, terutama pada waktu akhir pekan. Perusahaan harus memberikan penawaran harga yang mampu bersaing dengan kompetitor lain, agar kepuasan pelanggan dan keputusan pembelian produk yang ditawarkan meningkat. Perusahaan juga harus bisa, menjadikan pelanggan dan konsumen loyal terhadap tangki air Penguin pada Toko Bahan Bangunan di Gading Serpong, dengan cara memberikan pelayanan yang baik lagi terhadap pelanggannya.

\section{DAFTAR PUSTAKA}

\section{Buku}

Kotler, Philip., Gary, Armstrong. (2017). Prinsip-Prinsip Pemasaran. Jilid Edisi 12. Jakarta. Penerbit Erlangga

Kotler, Philip., Kevin, Lane Keller. (2016). Marketing Managemen,15th Editon,Pearson Education,Inc. 
Sawono, Jonathan. (2012). Model-Model Linier dan Non Linier Dalam IBM SPSS 21. Jakarta. Penerbit Gramedia

Sugiyono. (2017). Metode Penelitian Kuantitatif, Kualitatif dan R\&D. Bandung. Penerbit Alfabeta

Sumarni, Murti., Soeprihanto, John. (2014). Pengantar Bisnis (Dasar - dasar Ekonomi Perusahaan). Edisi 6. Yogyakarta. Liberty Yogyakarta

Sule, Tisnawati Erni., Saefullah, Kurniawan. (2017). Pengantar Manajemen. Edisi 1. Jakarta. Penerbit Kencana Prenada Media Group

Tjiptono, Fandy. (2016). Pemasaran Jasa. Edisi I. Yogyakarta.Penerbit Andi.

\section{Jurnal}

Koestanto, Hari., Tri. (2014). Pengaruh Kualitas Layanan TerhadapKepuasan Pelanggan Pada PT. BANK Jatim Cabang Kampus Surabaya. Jurnal IImu dan Riset Manajemen. Volume:3. No.10

Kumar, S Arun. (2010). "Influence of Services Quality on Attitudinal Loyalty Private Retail Banking, an Emperical study. The IOP Journal of Management Research. Volume:IX No. 4

\section{Via Website}

https://www.google.com/search?q=mitra+10+gading+serpong\&oq=mitra10.htm. Diakses via internet pada tanggal 10 Oktober 2019 pada pukul 10:20 wib.

https://www.csahome.com/id/tentang-kami/perusahaan.html. Diakses via internet pada tanggal 8 November 2019 pada pukul 08:30 wib. 